\title{
Pharmacological Treatment for Symptomatic Adenomyosis: A Systematic Review
}

\section{Tratamento farmacológico para adenomiose sintomática: revisão sistemática}

\author{
Cristina Laguna Benetti-Pinto ${ }^{10}$ Ticiana Aparecida Alves de Mira ${ }^{1}$ Daniela Angerame Yela ${ }^{1}$ \\ Cassia Raquel Teatin-Juliato ${ }^{1}$ Luiz Gustavo Oliveira Brito ${ }^{1}$
}

1 Department of Obstetrics and Gynecology, School of Medical Sciences, Universidade Estadual de Campinas, Campinas, SP, Brazil Rev Bras Ginecol Obstet 2019;41:564-574.
Address for correspondence Cristina Laguna Benetti-Pinto, MD, PhD, Alexander Fleming, 101, 13083-881, Cidade Universitária, Campinas, SP, Brazil (e-mail: laguna.unicamp@gmail.com).

\begin{abstract}
Objective To assess the efficacy of non-surgical treatment for adenomyosis. Data Sources A search was performed by two authors in the Pubmed, Scopus, and Scielo databases and in the grey literature from inception to March 2018, with no language restriction.

Selection of Studies We have included prospective randomized studies for treating symptomatic women with adenomyosis (abnormal uterine bleeding and/or pelvic pain) diagnosed by ultrasound or magnetic resonance imaging.

Data Collection Studies were primarily selected by title and abstract. The articles that were eligible for inclusion were evaluated in their entirety, and their data was extracted for further processing and analysis.

Data Synthesis From 567 retrieved records only 5 remained for analysis. The intervention groups were: levonorgestrel intrauterine system (LNG-IUS) $(n=2)$, dienogest $(n=2)$, and letrozole $(n=1)$. Levonorgestrel intrauterine system was effective to control bleeding when compared to hysterectomy or combined oral contraceptives (COCs). One study assessed chronic pelvic pain and reported that LNG-IUS was superior to COC to reduce symptoms. Regarding dienogest, it was efficient to reduce pelvic pain when compared to placebo or goserelin, but less effective to control bleeding than gonadotropin-releasing hormone $(\mathrm{GnRH})$ analog. Letrozole was as efficient as $\mathrm{GnRH}$ analog to relieve dysmenorrhea

\section{Keywords}

- adenomyosis

- abnormal menstrual bleeding

- pelvic pain

- systematic review

- medical treatment and dyspareunia, but not for chronic pelvic pain. Reduction of uterine volume was seen with aromatase inhibitors, GnRH analog, and LGN-IUD.

Conclusion Levonorgestrel intrauterine system and dienogest have significantly improved the control of bleeding and pelvic pain, respectively, in women with adenomyosis. However, there is insufficient data from the retrieved studies to endorse each medication for this disease. Further randomized control tests (RCTs) are needed to address pharmacological treatment of adenomyosis.
\end{abstract}

DCristina Laguna Benetti-Pinto's ORCID is https://orcid.org/00000001-6198-5593.

received

March 12, 2019

accepted

June 24, 2019
DOI https://doi.org/

$10.1055 / \mathrm{s}-0039-1695737$ ISSN $0100-7203$.
Copyright $\odot 2019$ by Thieme Revinter

Publicações Ltda, Rio de Janeiro, Brazil
License terms

(c) (1) 


\section{Resumo}

\section{Palavras-chave}

- adenomiose

- sangramento menstrual anormal

- dor pélvica

- revisão sistemática

- tratamento médico
Objetivo: Avaliar a eficácia de tratamento não cirúrgico para adenomiose. Fontes de dados: Uma pesquisa foi realizada por dois autores nas bases de dados Pubmed, Scopus, Scielo e na literatura cinzenta desde o início de cada base de dados até março de 2018, sem restrição de idioma.

Seleção de estudos: Incluímos estudos prospectivos randomizados para tratamento de mulheres sintomáticas com adenomiose (sangramento uterino anormal e/ou dor pélvica) diagnosticadas por ultrassonografia ou ressonância magnética.

Coleta de dados: Os estudos foram selecionados principalmente por título e resumo. Os artigos que preencheram os critérios de inclusão foram avaliados na íntegra, e seus dados foram extraídos para posterior processamento e análise.

Síntese dos dados: De 567 registros recuperados, somente 5 permaneceram para análise. Os grupos de intervenção foram: sistema intrauterino de levonorgestrel (SIU-LNG) $(n=2)$, dienogest $(n=2)$, e letrozol $(n=1)$. O SIU-LNG foi efetivo no controle do sangramento quando comparado à histerectomia ou aos contraceptivos orais combinados (COCs). Um estudo avaliou a dor pélvica crônica e relatou que o SIU-LNG foi superior ao COC para reduzir os sintomas. Em relação ao dienogest, este foi eficiente em reduzir a dor pélvica quando comparado ao placebo ou à goserelina, mas foi menos eficaz no controle do sangramento do que o análogo do hormônio liberador de gonadotropina (GnRH). O letrozol foi tão eficiente quanto o análogo do $\mathrm{GnRH}$ para aliviar a dismenorreia e a dispareunia, mas não para a dor pélvica crônica. Redução do volume uterino foi observada com inibidores de aromatase, análogo de GnRH, e SIU-LNG.

Conclusão: O SIU-LNG e dienogest apresentaram bons resultados para o controle de sangramento e dor pélvica, respectivamente, em mulheres com adenomiose. No entanto, não há dados suficientes para endossar cada medicação para tratar essa doença. Futuros estudos randomizados são necessários para avaliar o tratamento farmacológico da adenomiose.

\section{Introduction}

Adenomyosis is a benign disorder in which basal endometrial glands and stroma are found in the myometrium with reactive hyperplasia of the surrounding smooth muscle myometrial cells. ${ }^{1-5}$ It is a complex, gynecological condition with unknown incidence and etiology. Clinical symptoms are related to pain and bleeding, and they include dysmenorrhea, abnormal uterine bleeding, chronic pelvic pain (CPP), dyspareunia, and infertility; however, a third of women can be asymptomatic. ${ }^{6}$ Symptoms typically are reported to develop between the ages of 40 and 50 years; however, this may reflect the fact that the usual moment for diagnosing adenomyosis has been after performing a hysterectomy because of preoperative difficulty to establish the diagnosis. With improvement of diagnostic methods, like magnetic resonance imaging (MRI) and highquality transvaginal ultrasound (TVUS), early diagnosis can be made with an accuracy of 80 to $90 \%^{7-11}$

Non-surgical treatment can be necessary or desirable for women who want to maintain the uterus for a future pregnancy, those with other comorbidities that pose a higher risk for surgery, or even those who are close to menopause and would not like to undergo a surgical procedure. There are systematic reviews about uterine artery embolization, fertility-sparing treatment in patients with infertility, and local excision of adenomyosis. ${ }^{12-14}$ A published review about medical treatment for adenomyosis has presented their data narratively, since the author states that the aim was to discuss the medical approach to the management of adenomyosis symptoms, with no analysis of the risk of bias and methodological quality. ${ }^{15}$ Given the need for systematic reviews and quality assessment for analyzing these data, we sought to perform a systematic review of the effectiveness of non-surgical treatment for adenomyosis on uterine volume, pelvic pain, and menstrual bleeding, when compared with other surgical and non-surgical interventions.

\section{Methods}

\section{Study Design, Data Search, Inclusion/Exclusion Criteria}

The present review was recorded in the International Prospective Register of Systematic Reviews (PROSPERO) ${ }^{16}$ under the number CRD42017057896 and was developed according to Preferred Reporting Items for Systematic Reviews and Meta-Analyses (PRISMA). ${ }^{17}$

Searches in the databases included articles from the following sources: Pubmed, Scopus, Scielo, and the grey 
literature. Two authors (L. G. O. B. and T. A. A. M.) performed a distinct search using the following strategic combination of keywords: " "medical treatment" OR "clinical treatment" OR "hormone treatment" OR goserelin OR leuprolide OR GnRH OR “GnRH analog” OR “GnRH antagonist” OR progesterone OR Dienogest OR desogestrel OR COC OR "oral contracept" OR "non-surgical treatment" OR levonorgestrel OR drug OR medroxyprogesterone OR mifepristone OR sprm OR ulipristal OR progestin OR "combined oral contraceptive" OR aromatase OR letrozole OR anastrozole (adenomyosis)) NOT (animals OR children). All articles inserted in these databases were included up to March 2018.

We have included in this review prospective randomized and non-randomized studies with symptomatic women with image diagnosis (ultrasound [US] or MRI) suggestive of adenomyosis who were submitted to medical treatment versus any other comparator group. The main symptoms were: abnormal uterine bleeding, pain and/or changes in uterine volume. There were no restrictions regarding the language. We have excluded studies with no control group, with cross-sectional or case-control designs, case series, or retrospective studies.

\section{Primary and Secondary Outcomes}

Our primary outcomes were: menstrual bleeding through any kind of measurements, like hemoglobin $(\mathrm{Hb})$ by laboratory test or number of pads/days by the number of protector changes per day according to women's report; pelvic pain through the visual analogue scale (VAS); and reduction of uterine volume measured in milliliters or cubic centimeters by TVUS or MRI.

Quality of life was the secondary outcome, which was measured by questionnaires such as the World Health Organization Quality of Life (WHOQOL) short version or the Medical Outcomes Study (MOS).

Studies were primarily selected by title and abstract by the same authors that conducted the searches. Thus, articles that presented the eligibility criteria were evaluated in their entirety, and their data was extracted for further processing and analysis. Possible disagreements were discussed with a third author (C. L. B. P.) to obtain a consensus. The reviewers sought data that were not possible to obtain after reading the manuscript after an e-mail sent to the authors.

\section{Statistical analysis}

We tabulated mean difference (MD) and their standard deviations (SDs) between pre and posttreatments and their confidence intervals from continuous variables. In order to build forest plots, a mathematical calculation of error propagation was used, according to the author, ${ }^{18}$ to identify the SDs not described in some of the studies included in the present review after unanswered contact with the authors, once the publication did not mention these data. It was not possible to conduct a meta-analysis by the differences of the studies heterogeneity of the studies regarding the proposed treatments, because each study assessed a different treatment with or without a different comparator, and a single paired comparison was not present in more than one study. As the number of studies was scant, an indirect meta- analysis was not considered either. Funnel plots (publication bias) were not elaborated due to the scant number of retrieved studies. The risk of bias in the studies was assessed using the Cochrane bias risk assessment tool, ${ }^{19}$ which classifies studies at risk of low, high, or unclear bias. The Grading of Recommendations Assessment, Development and Evaluation (GRADE) criteria ${ }^{20}$ were used to build a summary of findings (SOF) table to evaluate the quality of the evidence.

\section{Results}

\section{Study Selection and Characteristics}

-Figure 1 describes the flowchart regarding the studies that comprise the present review. From 567 records that were retrieved in this search, 5 were removed due to duplication, 562 were screened, and 11 were fully assessed for eligibility, but only 5 remained in the final model. - Table 1 displays all selected studies that comprised 288 women; a total of 267 women completed the treatment and were included in the final results. No studies have mentioned whether their results were interpreted by intention-to-treat or per protocol analysis.

In summary, three from the five studies were held in Egypt, four presented a randomized controlled design, ${ }^{21-25}$ and one was prospective, non-randomized. ${ }^{24}$ One study was placebocontrolled, ${ }^{25}$ and the others were pharmacological treatments versus surgery or other drugs for adenomyosis. Transvaginal ultrasound diagnosis was present in all studies, and MRI was added as an option to TVUS in two studies. ${ }^{21-24}$ The duration of treatment varied from 4 weeks to 12 months. The intervention $\mathrm{x}$ comparator groups were: levonorgestrel intrauterine system (LNG-IUS) versus hysterectomy ${ }^{21}$; LNG-IUS versus combined oral contraceptive $(\mathrm{COC})^{23}$; letrozole versus goserelin ${ }^{22}$; dienogest versus triptorelin ${ }^{24}$; dienogest versus placebo. ${ }^{25}$ Some side effects of using pharmacological treatment were mentioned in all studies except one. ${ }^{24}$ - Figure 2 condenses all forest plots from the analyzed outcomes. From our planned primary outcomes, almost all of them (4 of 5) were present.

\section{Treatment with LNG-IUS}

Two studies have assessed the use of LNG-IUS ${ }^{21,23}$ versus hysterectomy or combined oral contraceptive (COC), respectively. In the first study, the LNG-IUS was effective to control bleeding, with an improvement of hemoglobin levels, and reduction in the number of days with bleeding. In the second study, a reduction in the number of days with bleeding was observed. Compared to the other medical treatment using COC, the bleeding pattern was improved in both arms; in the case of LNG-IUS, the mean number of bleeding days per month decreased from $9.81 \pm 1.82$ days before recruitment to $2.63 \pm 2.13$ days after the $6^{\text {th }}$ month of insertion $(p<0.001)$. In the COCs group, the number of bleeding days per month reduced from $9.97 \pm 1.52$ days to $5.52 \pm 1.00$ days $(p<0.001)$.

Pelvic pain was assessed in one study, ${ }^{23}$ and the LNG-IUS was more efficient in the improvement of chronic pelvic pain than $\operatorname{COC}(6.23 \pm 0.67-1.68 \pm 1.25-p<0.001)$, as well as the reduction in uterine volume $(10.23 \pm 1.06 \mathrm{~mL}-7.63 \pm 0.49 \mathrm{~mL}$, $p<0.001)$. 


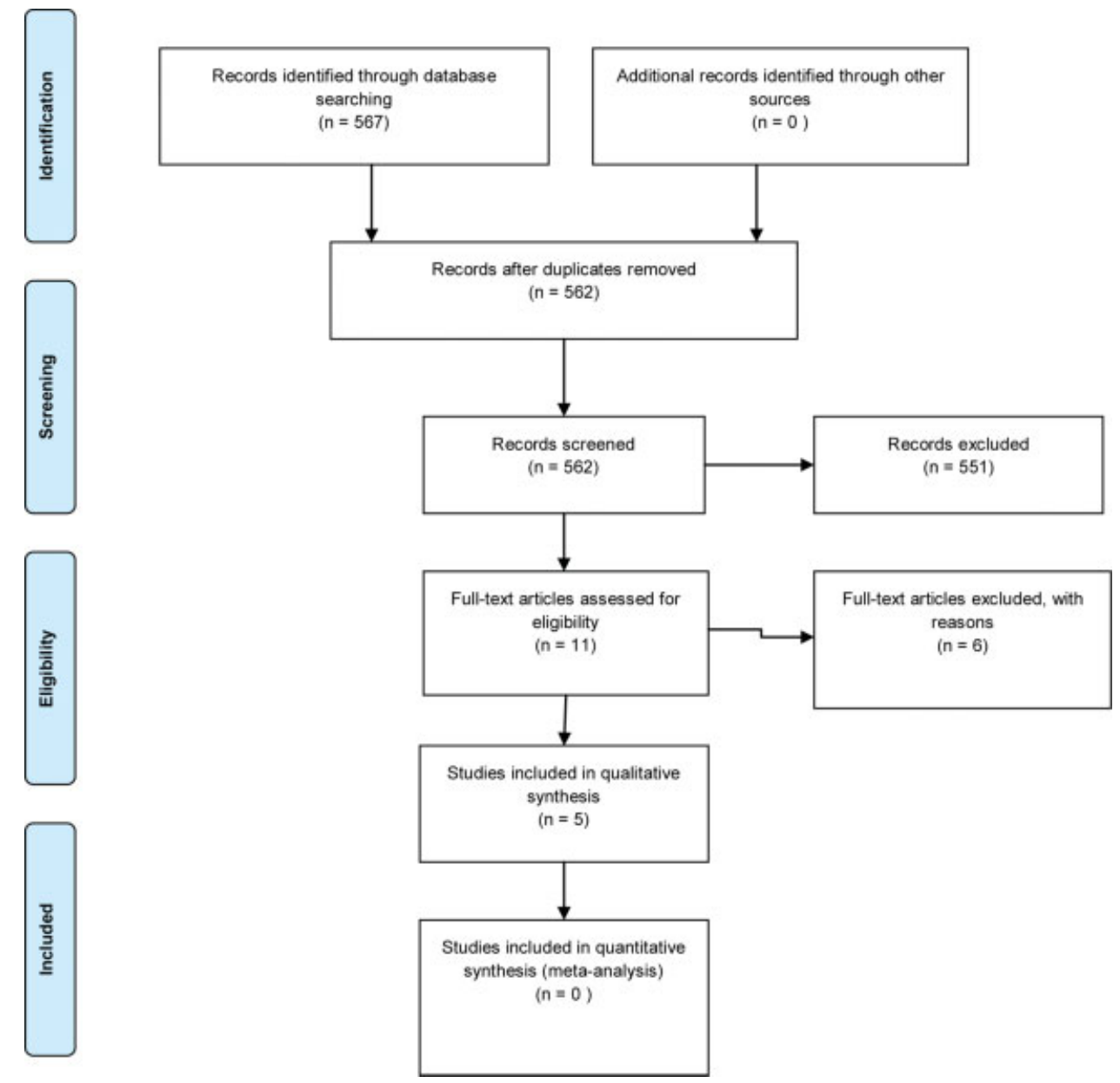

Fig. 1 Flow diagram describing the search and study inclusion processes.

Only one study assessed improvement of quality of life, ${ }^{21}$ with superior effects on psychological and social life with LNG-IUS when compared to hysterectomy. Women that used LNG-IUS presented adverse effects: headache (11.9\%), breast tenderness $(7.1 \%)$, acne (4.8\%), and transient depressive episode (2.4\%).

\section{Treatment with an Aromatase Inhibitor (Letrozole)}

Only one study ${ }^{22}$ evaluated letrozole in the treatment of adenomyosis compared to the GnRH analog goserelin. Letrozole was as efficient as goserelin to relieve dysmenorrhea $(p=0.48)$ and dyspareunia $(p=0.70)$, but the CPP control was statistically higher with goserelin $(p=0.04)$. Regarding the control of bleeding and the reduction of uterine volume, both medications presented similar response, but more side effects (hot flushes) were reported with goserelin (81.3\%).

\section{Treatment with Gonadotropin-releasing Hormone Agonist (GnRH Analog: Goserelin or Triptorelin Acetate)}

Two studies evaluated the use of GnRH analog: one compared to an aromatase inhibitor (goserelin X letrozole), ${ }^{22}$ and the other compared to dienogest (triptorelin X dienogest). ${ }^{24}$

The GnRH analog was more efficient than the aromatase inhibitor in controlling CPP $(p=0.04)$, but they were equally efficient in the control of dysmenorrhea and dyspareunia. When compared to dienogest, the GnRH analog was more efficient in controlling dysmenorrhea at 16 weeks ( $30.6 \pm 18.4$ versus $0.0, p<0.0001$ ) but equally efficient at reducing dyspareunia and CPP. Regarding bleeding control, the GnRH analog did not present a statistical difference when compared to letrozole; conversely, it was superior to dienogest. Finally, regarding the reduction of uterine volume, the $\mathrm{GnRH}$ analog and aromatase inhibitor were equivalents; ${ }^{18}$ however, when compared with dienogest, the GnRH analog was more efficient. ${ }^{21}$ One study evaluated side effects, having reported hot flushes in $81.3 \%$ of women treated with GnRH analog. ${ }^{22}$

\section{Treatment with dienogest}

Two studies evaluated dienogest; one compared to $\mathrm{GnRH}$ analog (triptorelin) ${ }^{24}$ and the other compared to placebo. ${ }^{25}$ Dienogest was efficient in both studies to reduce pain complaints (dysmenorrhea, dyspareunia, and CPP). When dienogest was compared to the GnRH analog (triptorelin), both were similar to control dyspareunia $(20.7 \pm 16.5$ versus $25.8 \pm 19.1, p=0.3899)$ and CPP $(21.7 \pm 11.6$ versus $24.5 \pm$ $13.8, p$-value $=0.5076$ ). There was a significant difference in the posttreatment dysmenorrhea between dienogest and triptorelin at 16 weeks, when the GnRH analog presented a better result $(30.6 \pm 18.4$ versus $0.0, p<0.0001)$. 


\begin{tabular}{|c|c|c|c|}
\hline$\frac{8}{5}$ & 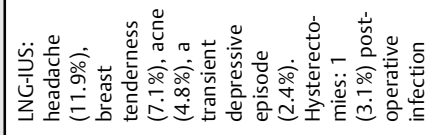 & 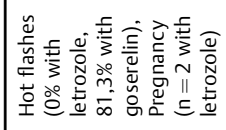 & 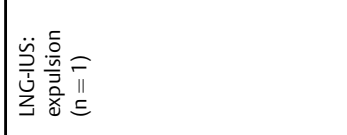 \\
\hline 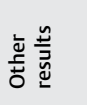 & & & 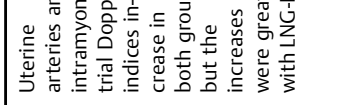 \\
\hline 高 & 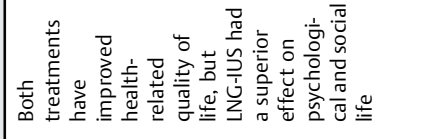 & & \\
\hline 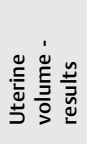 & 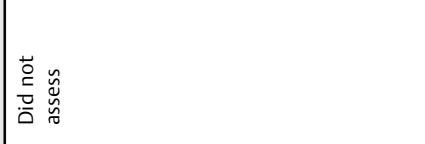 & 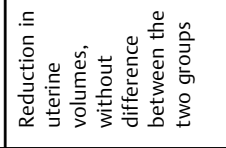 & 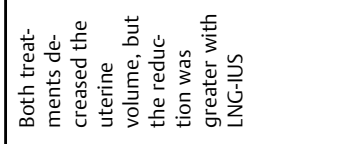 \\
\hline 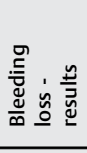 & 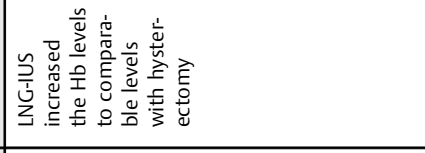 & 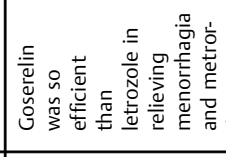 & 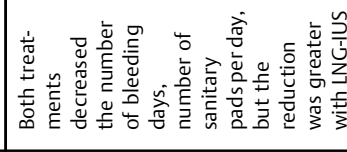 \\
\hline 它䇏 & 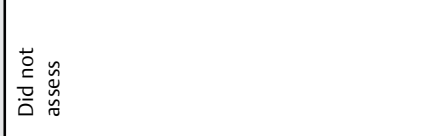 & 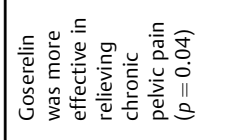 & 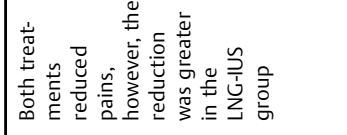 \\
\hline 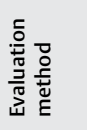 & 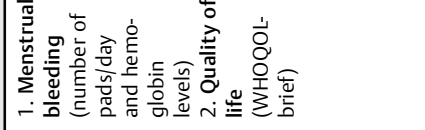 & & 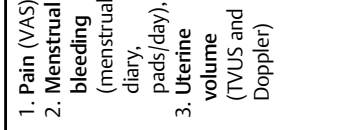 \\
\hline 产 & 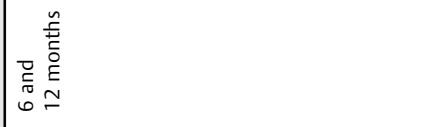 & 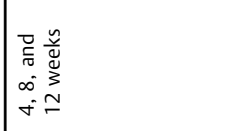 & 善 \\
\hline 䓂 & 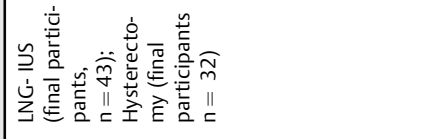 & 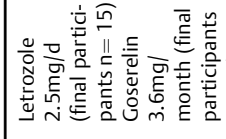 & 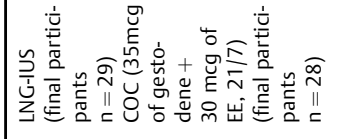 \\
\hline 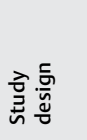 & 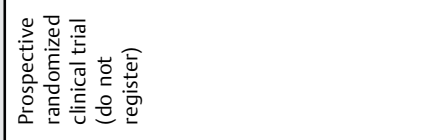 & 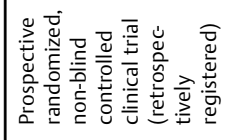 & 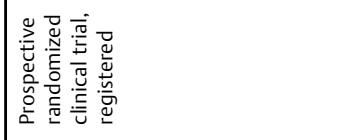 \\
\hline 总 & 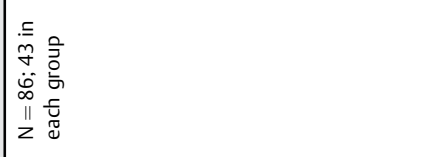 & $\begin{array}{l}\tilde{n} \\
\bar{n} \\
z\end{array}$ & 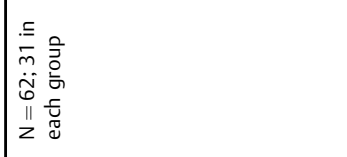 \\
\hline 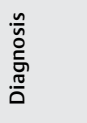 & 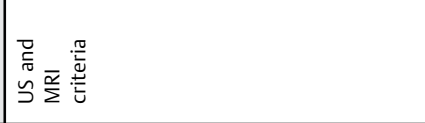 & 影 & 影 \\
\hline 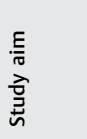 & 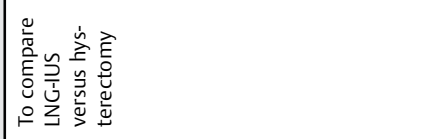 & 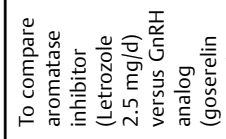 & 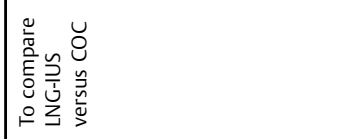 \\
\hline 衰 & 离 & 䇏 & 菩 \\
\hline 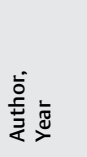 & 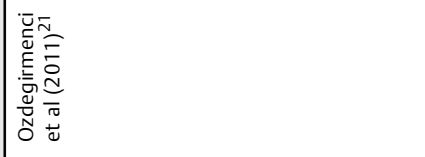 & 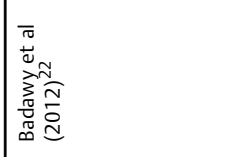 & 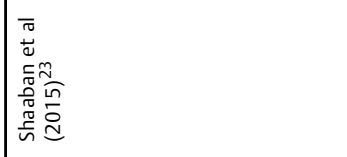 \\
\hline
\end{tabular}




\begin{tabular}{|c|c|c|}
\hline$\frac{\mathscr{n}}{\tilde{u}}$ & 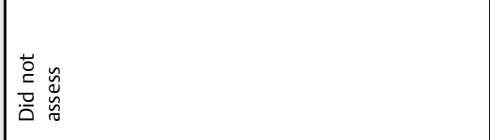 & 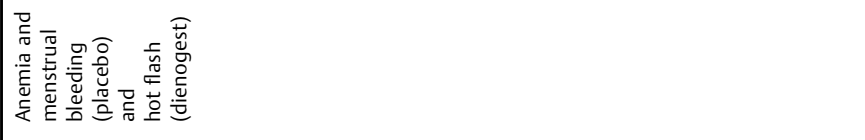 \\
\hline 产 & & 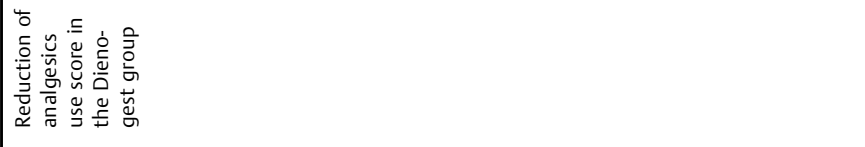 \\
\hline 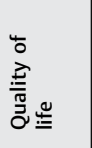 & & 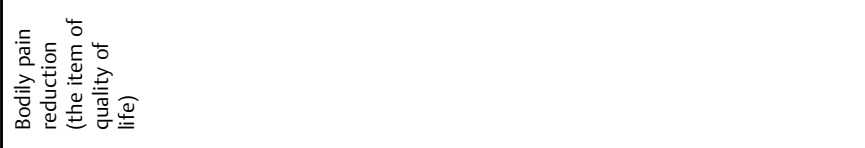 \\
\hline 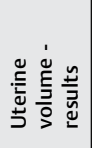 & 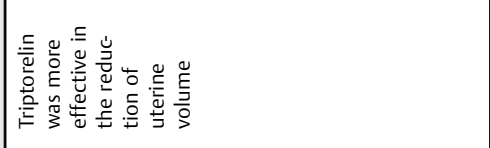 & 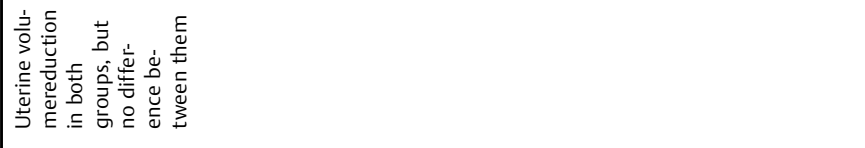 \\
\hline 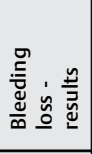 & 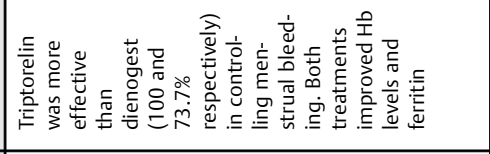 & 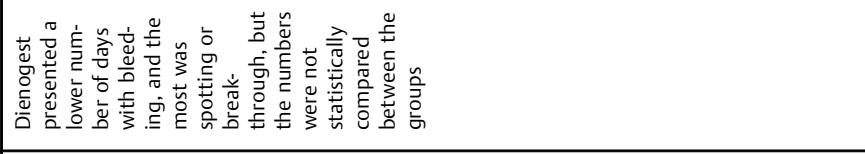 \\
\hline i & 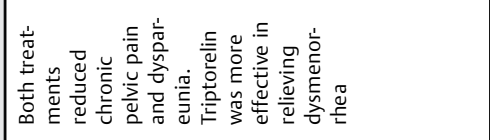 & 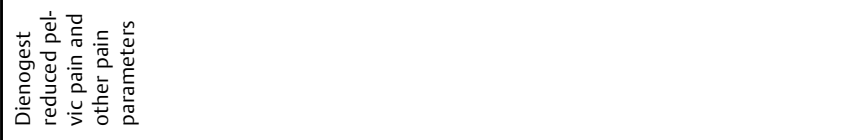 \\
\hline 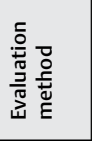 & 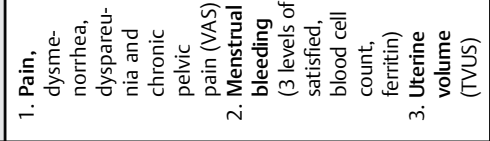 & 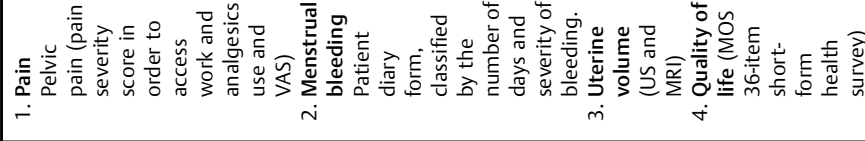 \\
\hline 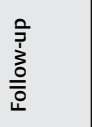 & 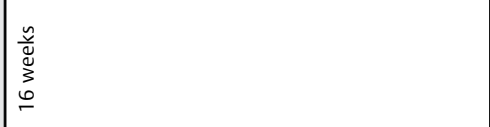 & 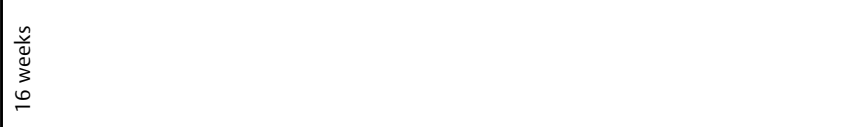 \\
\hline 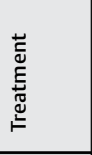 & 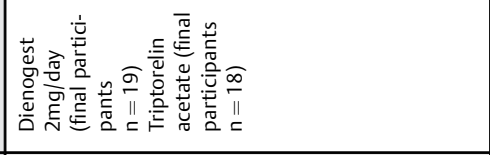 & 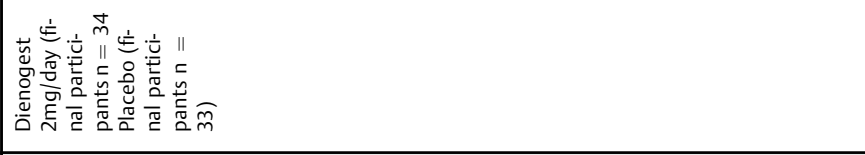 \\
\hline 咅高 & 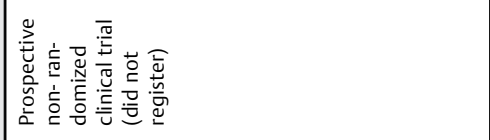 & 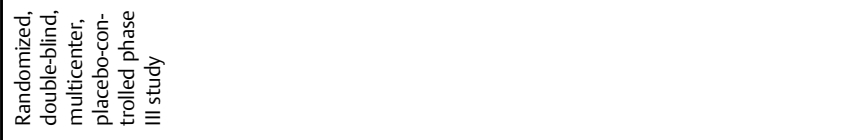 \\
\hline & 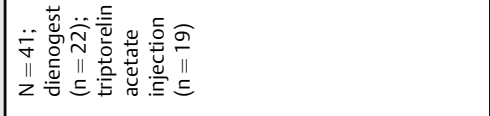 & $\begin{array}{l}0 \\
11 \\
z\end{array}$ \\
\hline $\begin{array}{l}\frac{n}{\overline{0}} \\
\frac{5}{5} \\
\frac{.0}{0}\end{array}$ & 结 & 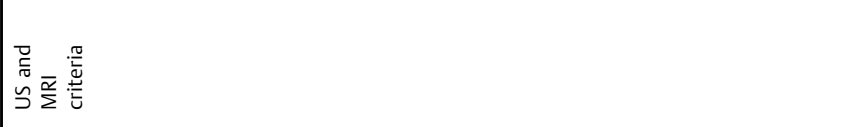 \\
\hline 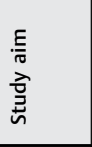 & 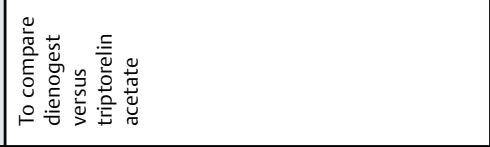 & 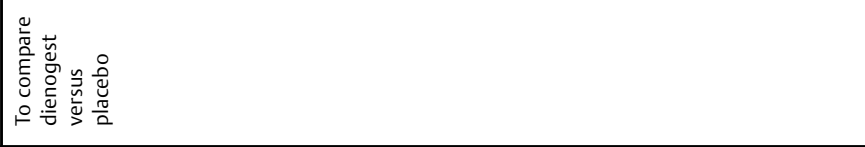 \\
\hline 章 & 营 & \begin{tabular}{|l} 
总 \\
竞
\end{tabular} \\
\hline 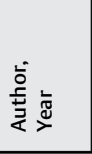 & 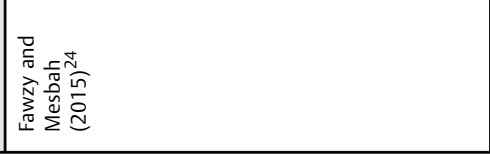 & 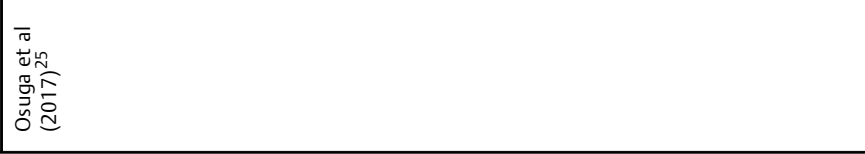 \\
\hline
\end{tabular}




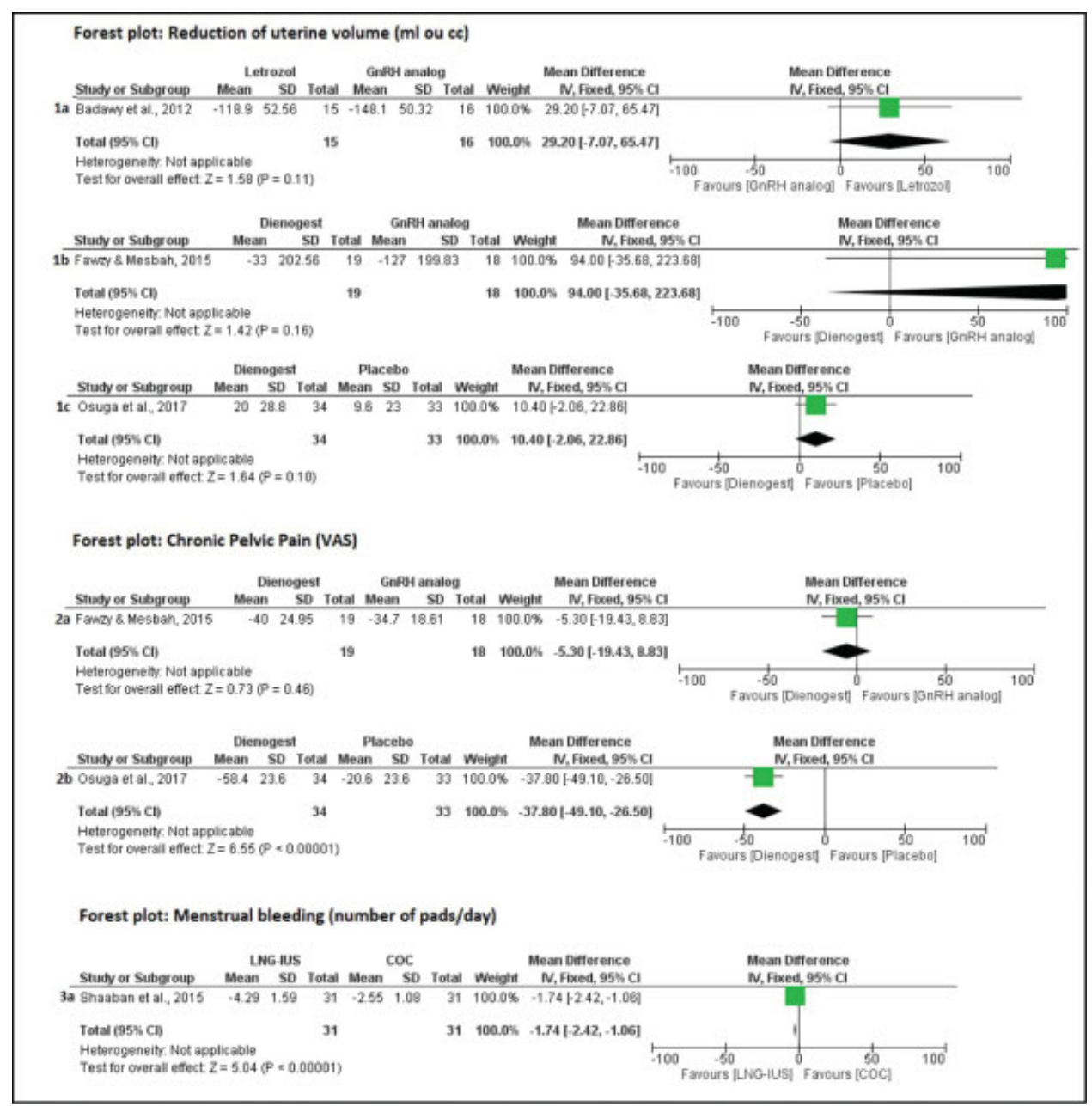

Fig. 2 Forest plot for the comparisons of the non-surgical treatments in the reduction of uterine volume, chronic pelvic pain, and menstrual bleeding.

Although bleeding control was reported by many women, dienogest maintained bleeding in $26.3 \%$ of women versus none from the GnRH group. ${ }^{24}$ Similarly, uterine volume was reduced according to 2 studies in women who used dienogest, but this reduction was lower than that obtained with the study that used GnRH analog $(278 \pm 162-151 \pm 117 \mathrm{ml}-$ $p=0.01){ }^{24}$ One of these studies ${ }^{25}$ reported hot flushes $(5.3 \%)$ as a side effect of the dienogest.

\section{Treatment with Combined Oral Contraceptives}

Only one study included one COC to treat adenomyosis, ${ }^{23}$ containing $75 \mathrm{mcg}$ of gestodene $+30 \mathrm{mcg}$ of ethynylestradiol, that was taken for 21 days with 7 days without the pills (21/7), compared to LNG-IUS. The results showed a reduction of pain $(6.55 \pm 0.68-3.90 \pm 0.54-p<0.001)$, decreased bleeding (numbers of days), and reduction of the uterine volume, but it was still less efficient that LNG-IUs for all evaluated parameters (pain - 6.23 $\pm 0.67-1.68 \pm 1.25-p<0.001$ ).

\section{Risk of Bias and Methodological Quality}

-Figure 3 discusses the risk of bias from the retrieved studies. Osuga et $\mathrm{al}^{25}$ presented the lowest risk of bias when analyzing all criteria from this table. Almost all studies (except Osuga et al) ${ }^{25}$ presented an unclear risk of bias for allocation concealment and selective reporting. Blinding was only possible in two studies (Osuga et $\mathrm{al}^{25}$ and Ozdergimenci et $\mathrm{al}^{21}$ ). About the GRADE criteria ( - Table 2 ), all variables presented a moderate certainty assessment, except menstrual bleeding (number of pads/day), comparing LNG-IUS versus COC for 6 months, that presented low certainty assessment. All studies presented serious imprecision due to the small number of events. Despite being sponsored by the pharmaceutical industry, the side effects of the Osuga et al study were reported, and, therefore, we do not consider that publication bias was low. Moreover, it was not possible to perform GRADE criteria for the study from Ozdergimenci et al due to inconsistencies, inaccuracy, and poor data description (it would not fit all the criteria for analyzing it).

\section{Discussion}

In the present systematic review, we have shown that the studied treatments (LNG-IUS, aromatase inhibitor [letrozole], GnRH agonist [goserelin and triptorelin], dienogest, and COC [75mcg of gestodene $+30 \mathrm{mcg}$ of ethinyl estradiol]), were efficient for the control of the two most common symptoms of adenomyosis: heavy menstrual bleeding and dysmenorrhea/ pelvic pain. Equally, regarding enlarged uterus, the treatments 


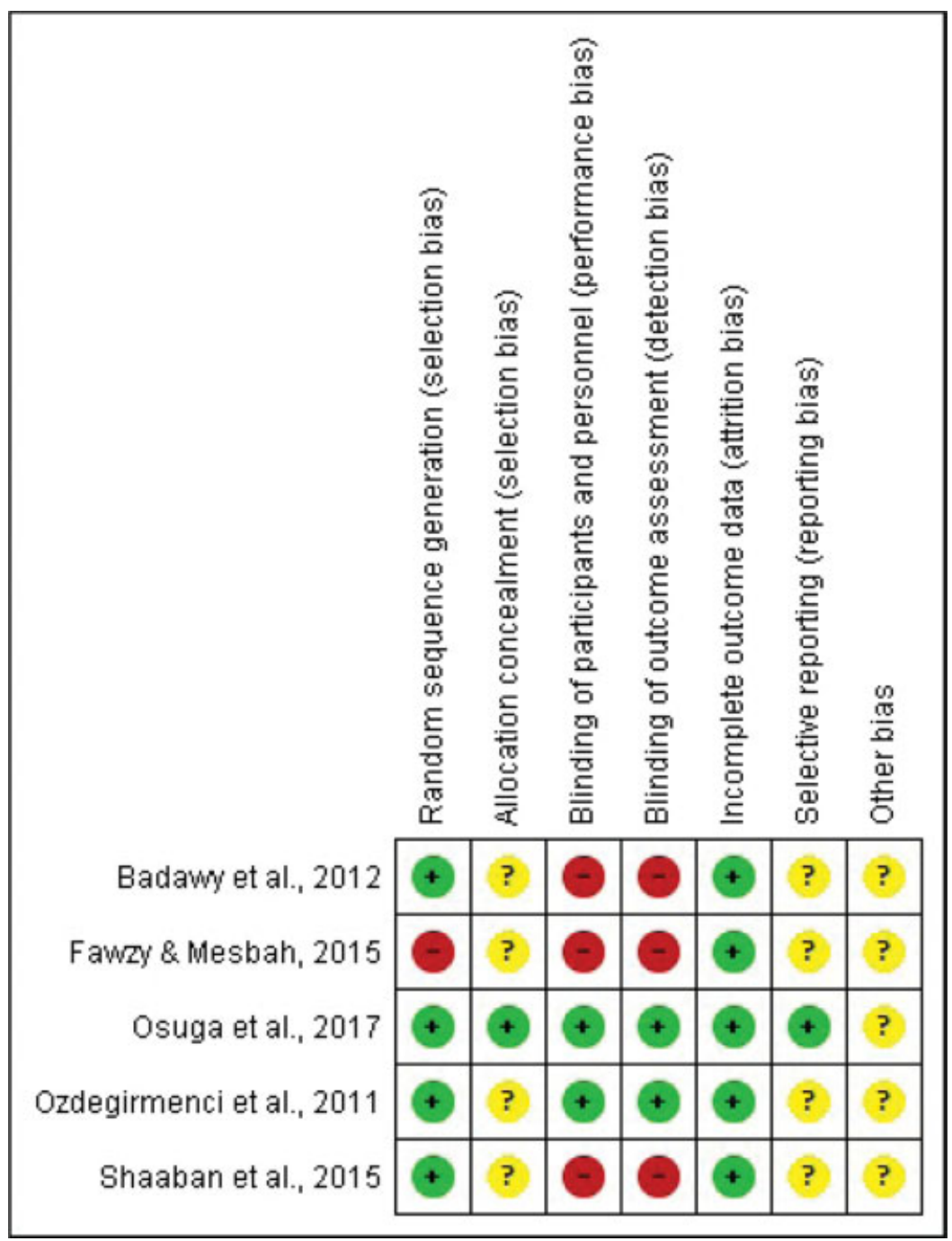

Fig. 3 Risk of bias summary $\Theta=$ high risk of bias; ? = uncertain risk of bias; $\oplus=$ low risk of bias.

promoted a reduction in the uterine volume. However, the number of retrieved studies is low and, according to the literature available up to this point, still not enough to endorse any of the analyzed treatments; the follow-up period of these studies was not long enough to permit a conclusion on how effective these treatments would be in the long term (only the LNG-IUS study presented a 12-month follow-up, which can be considered short to medium term). Unfortunately, we also noticed a lack of studies investigating the quality of life as a primary outcome; since most of the studies were concerned with objective outcomes (reduction of uterine volume, and number of days with abnormal bleeding); however, subjective improvement or patient satisfaction should also be considered. ${ }^{26,27}$ Moreover, the differences regarding intervention and comparator groups did not allow us to perform metanalysis or subgroup analysis.

The most frequent symptoms of adenomyosis are pelvic pain and abnormal uterine bleeding. Dysmenorrhea is present in 50 to $93 \%$ of women, while abnormal bleeding is present in 27 to $65 \% .{ }^{28}$ Despite the different comparators, it seems that the different pharmacological treatments evaluated, dienogest, COC, GnRH analog (triptorelin and goserelin), letrozole, and
LNG-IUS, were effective to reduce pelvic pain complaints and to reduce bleeding in women with adenomyosis. These results suggest that hormonal treatment improves the symptoms. The strengths of this review are: the inclusion of randomized controlled trials (RCTs) in a systematic review, and the quality assessment of these studies by the GRADE criteria. However, it is important to mention that our findings were limited by differences in the inclusion criteria of the studies, length of follow-up periods, different comparators, different scales used to measure blood volume loss or pelvic pain severity, which do not allow conclusions about delaying or avoiding surgical procedures. We have found another review in which the authors presented their data in a narrative format, citing the different available treatments. Also, in this publication, it is possible to visualize the difficulty of comparing treatments, limiting conclusions about pharmacological treatment. ${ }^{15}$ Therefore, the present study is the first systematic review evaluating the results from the pharmacological treatment in adenomyosis, with the intention to promote standardization of the methods and to fulfill gaps in the next prospective studies.

With the intention of standardizing future studies, in the present systematic review, we included below some 


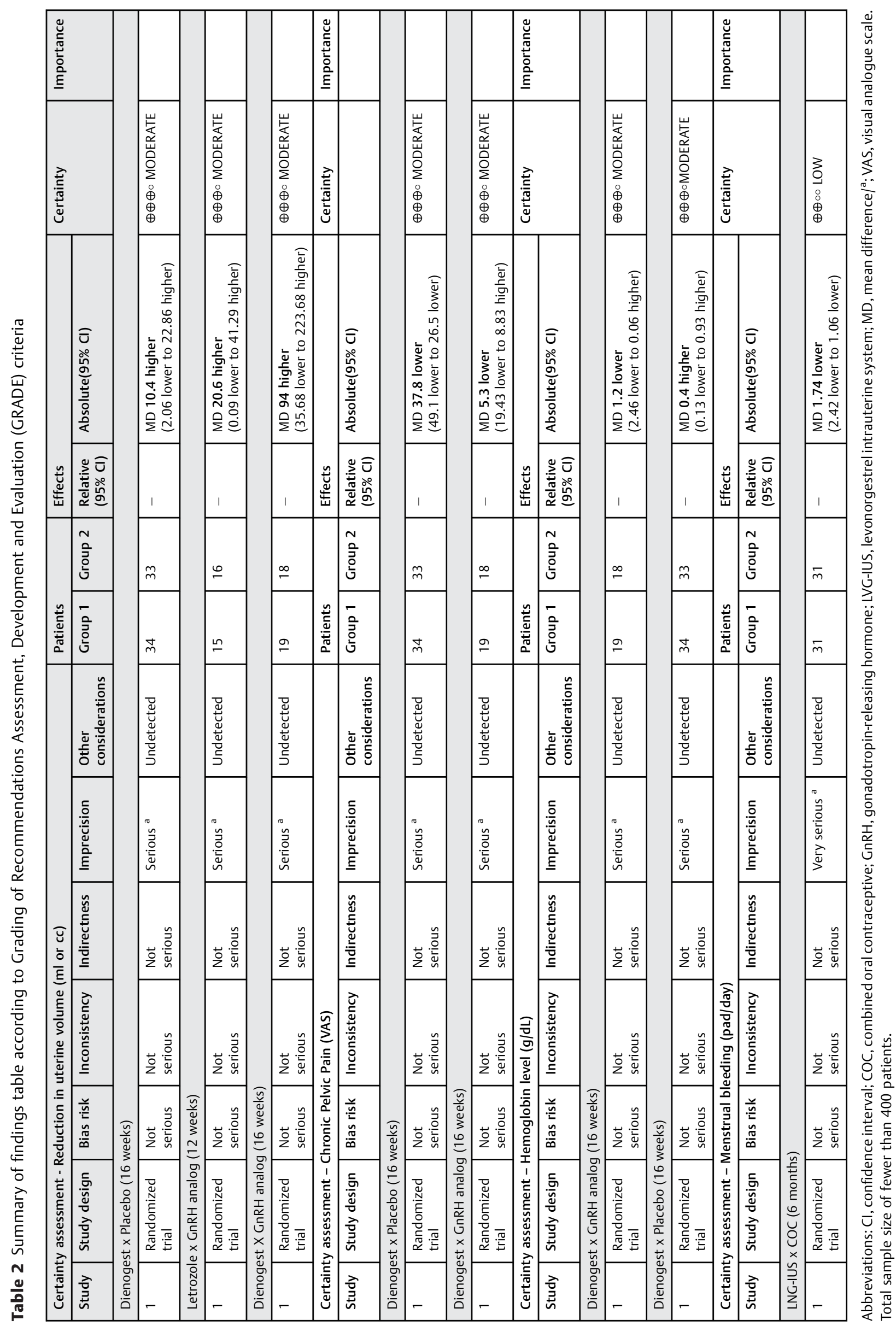


suggestions that could be considered important to be included during any checklist for preparing a prospective study for women with symptomatic adenomyosis. More studies are needed to allow comparisons, conclusions on long-term efficacy, and side effects that limit its use.

\section{Diagnosis}

To use pelvic US (preferably transvaginal probe-TVUS and 3DTVUS-when available) or MRI for the diagnosis of adenomyosis, ${ }^{28,29}$ describing the presence or absence of at least the following criteria:

- globular uterus with regular contours (US or MRI);

- asymmetrical thickening of the myometrial walls (US or MRI);

- thickening of the junctional zone (JZ) $\geq 12 \mathrm{~mm}$ (MRI or, eventually, by US);

- greatest JZ thickness to total myometrium ratio $>40$ to $50 \%$ (US or MRI);

- foci of high signal intensity running alongside the endometrium on T2 and sometimes also T1-weighted;

- images that persist on Fat-Sat (FS) (MRI);

- anechoic sub endometrial microcysts in the myometrium (around 2-4 mm in diameter) (US);

- description of association or not with leiomyoma.

\section{Uterine Volume}

- To perform the same imaging technique used for diagnosis, preferably at the same time that clinical complaints are re-evaluated, to correlate the results.

\section{Symptoms (Pain and Bleeding)}

- There is no specific questionnaire for adenomyosis

- To evaluate pain-related symptoms: pelvic pain, dysmenorrhea, and deep dyspareunia. The assessment criteria should include the VAS. When possible, make daily control diaries for each type of pain and register the frequency of pain.

- To evaluate bleeding symptoms through a scale with the number of days of bleeding and number of pads per 30day (interval). We suggest using the Pictorial Blood Assessment Chart (PBAC) and serum levels of hemoglobin and ferritin.

- Both symptoms (pain and bleeding) should be evaluated at the initial time before treatment, and every 4 months (120 days).

\section{Side Effects}

- To describe in detail all possible and unpredictable side effects, especially when these were indicative of discontinuation of treatment, including the number of losses.

- To report cases of non-response to pharmacological treatment.

\section{Quality of Life}

- To use the 36-item short-form survey (SF-36) or the WHOQOL questionnaire.

\section{Conclusion}

Levonorgestrel intrauterine system and dienogest presented good results for controling bleeding and pelvic pain, respectively, versus their comparators. However, there is insufficient data from the retrieved studies to endorse each medication for symptomatic adenomyosis. Future RCTs comparing pharmacological treatments for adenomyosis are needed to bolster the available data.

\section{Contributions}

All the authors participated actively in the study, as follows: Yela D. A., Benetti-Pinto C. L., and Brito L. G. O. were responsible for writing the protocol and the final manuscript. Teatin-Juliato C. R. and Mira T. A. A. collected the data and conducted a review of the literature.

Conflicts of Interest

The authors have no conflicts of interest to declare.

\section{References}

1 Levy G, Dehaene A, Laurent N, et al. An update on adenomyosis. Diagn Interv Imaging 2013;94(01):3-25. Doi: 10.1016/j.diii.2012. 10.012

2 Bazot M, Daraï E. Role of transvaginal sonography and magnetic resonance imaging in the diagnosis of uterine adenomyosis. Fertil Steril 2018;109(03):389-397. Doi: 10.1016/j.fertnstert.2018.01.024

3 Azziz R. Adenomyosis: current perspectives. Obstet Gynecol Clin North Am 1989;16(01):221-235

4 Brosens JJ, Barker FG, de Souza NM. Myometrial zonal differentiation and uterine junctional zone hyperplasia in the non-pregnant uterus. Hum Reprod Update 1998;4(05):496-502. Doi: 10.1093/humupd/4.5.496

5 Leyendecker G, Herbertz M, Kunz G, Mall G. Endometriosis results from the dislocation of basal endometrium. Hum Reprod 2002;17 (10):2725-2736. Doi: 10.1093/humrep/17.10.2725

6 Peric H, Fraser IS. The symptomatology of adenomyosis. Best Pract Res Clin Obstet Gynaecol 2006;20(04):547-555. Doi: 10.1016/j. bpobgyn.2006.01.006

7 Exacoustos C, Manganaro L, Zupi E. Imaging for the evaluation of endometriosis and adenomyosis. Best Pract Res Clin Obstet Gynaecol 2014;28(05):655-681. Doi: 10.1016/j.bpobgyn.2014.04.010

8 Dueholm M, Lundorf E. Transvaginal ultrasound or MRI for diagnosis of adenomyosis. Curr Opin Obstet Gynecol 2007;19 (06):505-512. Doi: 10.1097/GCO.0b013e3282f1bf00

9 Bergeron C, Amant F, Ferenczy A. Pathology and physiopathology of adenomyosis. Best Pract Res Clin Obstet Gynaecol 2006;20(04): 511-521. Doi: 10.1016/j.bpobgyn.2006.01.016

10 Valentini AL, Speca S, Gui B, Soglia G, Miccò M, Bonomo L. Adenomyosis: from the sign to the diagnosis. Imaging, diagnostic pitfalls and differential diagnosis: a pictorial review. Radiol Med (Torino) 2011;116(08):1267-1287. Doi: 10.1007/s11547-011-0714-5

11 Andres MP, Borrelli GM, Ribeiro J, Baracat EC, Abrão MS, Kho RM. Transvaginal ultrasound for the diagnosis of adenomyosis: systematic review and meta-analysis. J Minim Invasive Gynecol 2018;25(02):257-264. Doi: 10.1016/j.jmig.2017.08.653

12 Younes G, Tulandi T. Conservative surgery for adenomyosis and results: a systematic review. J Minim Invasive Gynecol 2018;25 (02):265-276. Doi: 10.1016/j.jmig.2017.07.014

13 Rocha TP, Andres MP, Borrelli GM, Abrão MS. Fertility-sparing treatment of adenomyosis in patients with infertility: a systematic review of current options. Reprod Sci 2018;25(04):480-486. Doi: $10.1177 / 1933719118756754$ 
14 de Bruijn AM, Smink M, Lohle PNM, et al. Uterine artery embolization for the treatment of adenomyosis: a systematic review and meta-analysis. J Vasc Interv Radiol 2017;28(12):1629-1642.e1. Doi: 10.1016/j.jvir.2017.07.034

15 Pontis A, D'Alterio MN, Pirarba S, de Angelis C, Tinelli R, Angioni S. Adenomyosis: a systematic review of medical treatment. Gynecol Endocrinol 2016;32(09):696-700. Doi: 10.1080/09513590.2016. 1197200

16 National Institute for Health Research. Prospero: International Prospective Register of Systematic Reviews. 2013. https://www. crd.york.ac.uk/prospero/. Accessed September 20, 2018.

17 Moher D, Liberati A, Tetzlaff J, Altman DG; PRISMA Group. Preferred reporting items for systematic reviews and meta-analyses: the PRISMA statement. BMJ 2009;339:b2535. Doi: 10.1136/bmj.b2535

18 Preston DW, Dietz ER. The Art of Experimental Physics. New York, NY: John Wiley \& Sons; 1991

19 Higgins JPT, Altman DG. Assessing risk of bias in included studies. In: Higgins JPT, Green S, eds. Cochrane Handbook for Systematic Reviews of Interventions. New York, NY: John Wiley \& Sons; 2008:187-241

20 Schünemann H, Brożek J, Guyatt G, Oxman A. GRADE Handbook for Grading Quality of Evidence and Strength of Recommendations. Hamilton: The GRADE Working Group; 2013https://gdt.gradepro. org/app/handbook/handbook.html. Accessed September 20, 2018.

21 Ozdegirmenci O, Kayikcioglu F, Akgul MA, et al. Comparison of levonorgestrel intrauterine system versus hysterectomy on efficacy and quality of life in patients with adenomyosis. Fertil Steril 2011;95(02):497-502. Doi: 10.1016/j.fertnstert.2010.10.009

22 Badawy AM, Elnashar AM, Mosbah AA. Aromatase inhibitors or gonadotropin-releasing hormone agonists for the management of uterine adenomyosis: a randomized controlled trial. Acta Obstet Gynecol Scand 2012;91(04):489-495. Doi: 10.1111/j.16000412.2012.01350.x
23 Shaaban OM, Ali MK, Sabra AM, Abd El Aal DE. Levonorgestrelreleasing intrauterine system versus a low-dose combined oral contraceptive for treatment of adenomyotic uteri: a randomized clinical trial. Contraception 2015;92(04):301-307. Doi: 10.1016/ j.contraception.2015.05.015

24 Fawzy M, Mesbah Y. Comparison of dienogest versus triptorelin acetate in premenopausal women with adenomyosis: a prospective clinical trial. Arch Gynecol Obstet 2015;292(06):1267-1271. Doi: $10.1007 /$ s00404-015-3755-5

25 Osuga Y, Fujimoto-Okabe H, Hagino A. Evaluation of the efficacy and safety of dienogest in the treatment of painful symptoms in patients with adenomyosis: a randomized, double-blind, multicenter, placebo-controlled study. Fertil Steril 2017;108(04): 673-678. Doi: 10.1016/j.fertnstert.2017.07.021

26 Elwyn G, O'Connor A, Stacey D, et al; International Patient Decision Aids Standards (IPDAS) Collaboration. Developing a quality criteria framework for patient decision aids: online international Delphi consensus process. BMJ 2006;333(7565):417. Doi: 10.1136/bmj.38926.629329.AE

27 Frank L, Basch E, Selby JV; Patient-Centered Outcomes Research Institute. The PCORI perspective on patient-centered outcomes research. JAMA 2014;312(15):1513-1514. Doi: 10.1001/jama.20 14.11100

28 Gordts S, Grimbizis G, Campo R. Symptoms and classification of uterine adenomyosis, including the place of hysteroscopy in diagnosis. Fertil Steril 2018;109(03):380-388.e1. Doi: 10.1016/ j.fertnstert.2018.01.006

29 Van den Bosch T, Dueholm M, Leone FP, et al. Terms, definitions and measurements to describe sonographic features of myometrium and uterine masses: a consensus opinion from the Morphological Uterus Sonographic Assessment (MUSA) group. Ultrasound Obstet Gynecol 2015;46(03):284-298. Doi: 10.1002/uog.14806 